\title{
SEVERE FACIAL REACTION TO THIURAMS IN SURGEONS
}

\author{
Luca Coppeta, Francesca Papa, Antonio Pietroiusti, Ludovico Maria De Zordo, Stefano Perrone, \\ Silvia Barone, Andrea Magrini
}

University of Rome “Tor Vergata," Rome, Italy

Department of Occupational Medicine

\begin{abstract}
Contact dermatitis is a major problem in the healthcare environment and in other sectors. Healthcare professionals may be exposed to a large number of chemical agents, including the accelerators for rubber vulcanization process. The prevalence of allergic contact dermatitis among operators in the sector ranges 13-30\%. This paper describes the case of a 46 -year-old male cardiac surgeon affected by a severe skin reaction localized on the face in the absence of hand dermatitis, presumably resulting from the use of a surgical patch applied to the face. Patch tests were performed and the result was negative for latex and positive (+++) for thiuram mix. A thiuram-free tape was prescribed and the operator's dermatitis improved significantly. Thus, it would be very important to pay attention to skin disorders in health workers and thiuram as an occupational allergen. Med Pr. 2019; $70(1): 121-4$
\end{abstract}

Key words: occupational dermatitis, allergy, contact dermatitis, concomitant contact sensitization, occupational allergens, thiurams

Corresponding author: Luca Coppeta, University of Rome “Tor Vergata,” Department of Occupational Medicine, Viale Oxford 81, 00133 Rome, Italy, e-mail: luca.coppeta@ptvonline.it

Received: January 8, 2018, accepted: May 17, 2018

\section{INTRODUCTION}

Allergic sensitization in the health sector represents a significant public health problem. For example, the prevalence of allergic contact dermatitis among operators in the sector ranges $13-30 \%$ [1]. Healthcare professionals may be exposed to a large number of chemical agents able to cause a wide spectrum of clinical manifestations that include urticaria, allergic contact dermatitis (ACD), and irritant contact dermatitis (ICD), as well as the aggravation of a series of endogenous diseases. The job stress would also play a significant role in triggering skin disorders among hospital workers [2].

Given the frequency of atypical manifestations, the occurrence of contact dermatitis among healthcare professionals may be underestimated in most areas of the sector. The implementation of targeted epicutaneous tests (patch tests) using relevant haptens [3] enables a more accurate diagnostic evaluation. Previous studies conducted on this topic have demonstrated positive patch test results of $17-63 \%$ for healthcare workers $[1,4,5]$, but the awareness framework has been changing over the last decades and is yet to be formally established.

The most frequently implicated substance in allergic reactions for health workers in the past was latex, which alone was responsible for most cases. Currently, the exclusion of the substance from the products in use and from the working cycles has been determined a success in terms of reducing cases of sensitization, which according to recent estimates is now between 2.8 $10.7 \%[6]$.

The attention of scholars is currently moving towards a series of allergens other than latex, which may also be involved in cases of sensitization amongst health workers. The most frequent of these are: thiuram mix, quaternary ammonium, formaldehyde, benzalkonium chloride, and nickel $[1,7-9]$.

The spectrum of clinical manifestations varies from urticarial reactions to eczematous dermatitis, and generalized, potentially serious reactions.

This study describes a case of an unusual allergic reaction in a healthcare professional operating in a university hospital.

\section{CASE REPORT}

A 46-year-old male health worker (cardiac surgeon) presented a florid central facial and periorbital dermatitis. The rash was erythematous, pruritic, and scaly. The worker had minimal dermatitis of the forearms, 
and no hand involvement. The rash occurred within a few hours after starting work in the operating theatre sessions, and improved with a lapse of time spent away from the workplace. He had no urticaria, angioedema, or respiratory symptoms, and his rash improved as a result of intramuscular administration of betamethasone $4 \mathrm{mg}$. The dermatitis had appeared in a milder form 2 days before, disappearing at the end of the work shift.

The operator reported the use of a facial surgical mask fixed with an adhesive plaster to prevent the misting of the magnifying glasses. He wore disposable, non-powdered surgical latex gloves.

Baseline blood tests, RIST and RAST for common allergens were performed using system Immunolite 2000 (Siemens, Germany); resulting negative. Sensitization to latex resulted negative (total IgE $9.24 \mathrm{IU} / \mathrm{ml}$, latexspecific $\operatorname{IgE}<0.10 \mathrm{IU} / \mathrm{mL})$.

Patch tests were performed with 40 haptens from the European Baseline Series (Euromedical s.r.l., Chemotechnique Diagnostics, Italy). Allergens were applied with Finn Chambers (Curatest F, Lohmann \& Rauscher, Germany). The patch was applied to the back of the subject (interscapular region) and removed $48 \mathrm{~h}$ after application. The application site was also revalued to $72 \mathrm{~h}$, in accordance with the guidelines of the International Contact Dermatitis Research Group. The result was positive $(+++)$ for thiuram mix (Figure 1), which was found in the surgical adhesive plaster used by the operator to fix a surgical mask to his glasses to prevent them becoming fogged. The patch used had recently been introduced into our hospital.

A thiuram-free tape was prescribed and the subject's dermatitis improved significantly. He subsequently used an accelerator-free tape and gloves and remained symptom-free.

\section{DISCUSSION}

Allergic contact dermatitis is a common problem for healthcare personnel, and artificial rubber is commonly implicated; in particular, the accelerators for rubber vulcanization processes, out of which thiurams are among the most commonly implicated substances.

The frequency of sensitization to these compounds is increasing in the health sector and the spectrum of the most varied cutaneous manifestations [10-12]. Severe cases of ACD with involvement of the periorbital area, edema of the face and scalp, and even with airway involvement have been described in the litera-

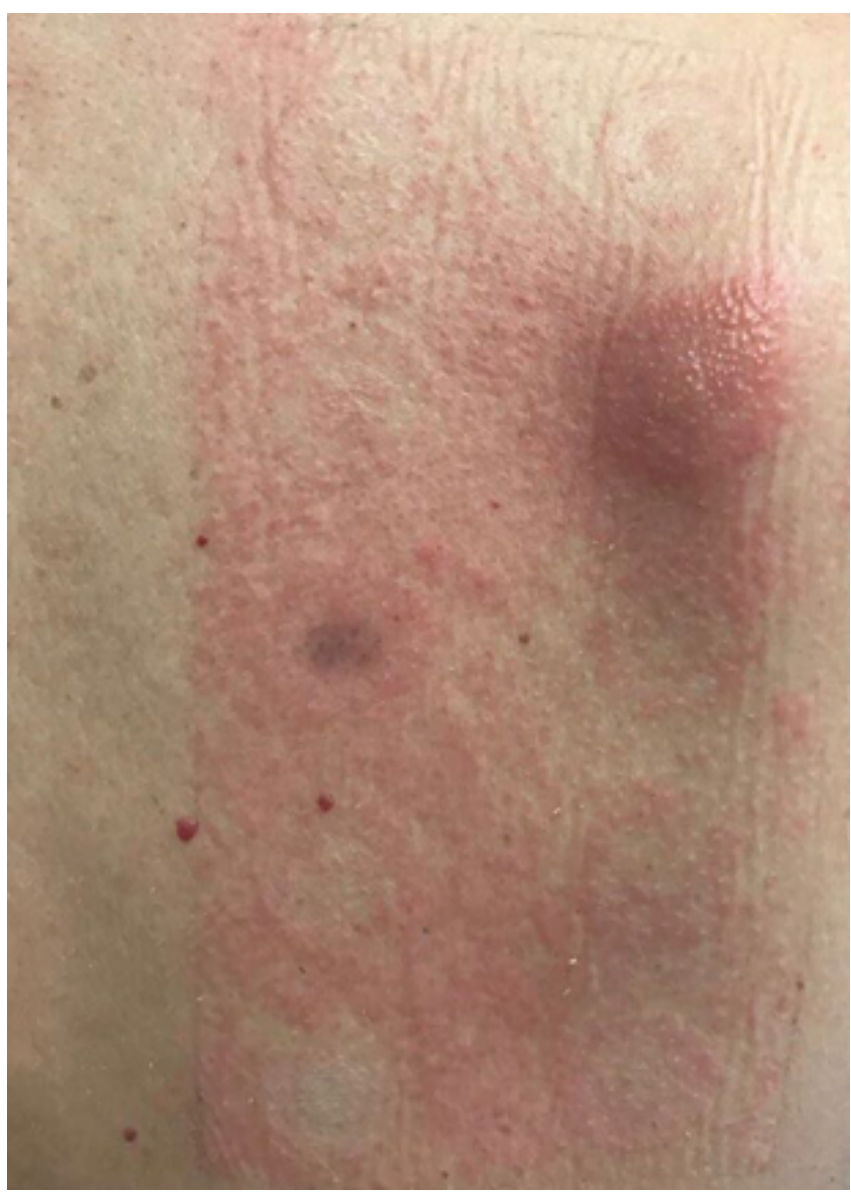

Figure 1. Positive patch test $(+++)$ to thiuram mix

ture related to sensitization to various substances, such as PPD $[13,14]$ and i.e., they may be confused at the onset with hypersensitivity reactions of type I. In at least one case described there was a concurrent reproducibility of positive thiuram patch tests.

The facial manifestation of severe rubber contact dermatitis is quite unusual; only a few cases have been described in the literature [15-17] without the concurrent involvement of the hands. In particular, in two cases described, the erythema of the face and periorbital area represented the only manifestation of dermatitis linked to the use of synthetic rubber gloves and was solved by the use of accelerator-free nitrile gloves.

Tissue sensitization cases related to the use of surgical gloves and adhesive patches have been described in both operators and patients $[18,19]$, but very rarely with face involvement in the absence of hand dermatitis. In a survey conducted among health professionals regarding the presence of problems related to the use of rubber gloves, cases of periorbital dermatitis without symptoms of the hands were reported [20]. The 
case of a midwife with facial edema linked to the use of rubber gloves has also been described; it has been hypothesized that the frequent change of gloves and the contact of the hands with the eyelids may have favored the deposition of sensitizing substances at this level [21].

In that case, the sensitization could have happened in all these ways, but the localization of the erythema and the relationship with the exposure (cessation of the manifestation after having forbidden the operator to use the surgical patch) seem to deposit due to the presence of a sensitization to the substances contained in the adhesive film. In any case, the negative results for the serum and cutaneous test for latex was an indispensable element in the differential diagnosis.

The operator no longer showed symptoms after abandoning the use of the surgical patch on the face and after using accelerator-free gloves.

\section{CONCLUSIONS}

To our knowledge, this is a rare report of severe facial dermatitis without hand involvement in the case of a surgeon with a positive thiuram patch test result. Thus, it would be very important to pay more attention to thiuram as an occupational allergen. The symptomatic operators for contact dermatitis should always be tested and accelerator-free products should be prescribed to those subjects with diagnosed allergy to thiurams.

Furthermore, skin disorders are very common not only among health workers, but also in other sectors, so the occupational doctor should always make a careful assessment, looking for the associations between symptoms and the work environment [22].

\section{REFERENCES}

1. Kadivar S, Belsito DV. Occupational dermatitis in health care workers evaluated for suspected allergic contact dermatitis. Dermatitis 2015;26(4):177-83, https://doi.org/10. 1097/DER.0000000000000124.

2. Magnavita N, Elovainio M, Heponiemi T, Magnavita AM, Bergamaschi A. Are skin disorders related to work strain in hospital workers? A cross-sectional study. BMC Public Health. 2011;11:600, https://doi.org/10.1186/1471-2458$11-600$.

3. Visser MJ, Verberk MM, van Dijk FJ. Wet work and hand eczema in apprentice nurses: Part I of a prospective cohort study. Contact Dermat. 2014;70(1):44-55, https://doi. org/10.1111/cod.12131.
4. Tanno LK, Darlenski R, Sánchez-Garcia S, Bonini M, Vereda A, Kolkhir P, et al. International survey on skin patch test procedures, attitudes and interpretation. World Allergy Organ J. 2016;9:1-10, https://doi.org/10.1186/ s40413-016-0098-z.

5. Nettis E, Marcandrea M, Colanardi MC, Paradiso MT, Ferrannini A, Tursi A. Results of standard series patch testing with occupational allergic contact dermatitis. Allergy. 2003;58(12):1304-7.

6. Nettis E, Colanardi MC, Soccio AL, Soccio AL, Ferrannini A, Tursi A. Occupational irritant and allergic contact dermatitis among health care workers. Contact Dermat. 2002;46(2):101-7.

7. Suneja T, Belsito DV. Occupational dermatoses in health care workers evaluated for suspected allergic contact dermatitis. Contact Dermat. 2008;58(5):285-90, https://doi. org/10.1111/j.1600-0536.2007.01315.x.

8. Higgins CL, Palmer AM, Cahill JL, Nixon RL. Occupational skin disease among Australian healthcare workers: A retrospective analysis from an occupational dermatology clinic, 1993-2014. Contact Dermat. 2016;75(4):21322, https://doi.org/10.1111/cod.12616.

9. Schwensen JF, Menné T, Sommerlund M, Andersen KE, Mortz CG, Zachariae C, et al. Contact allergy in danish healthcare workers: A retrospective matched case-control study. Acta Derm Venereol. 2016;96(2):237-40, https:// doi.org/10.2340/00015555-2202.

10. Prodi A, Rui F, Fortina AB, Corradin MT, Filon FL. Healthcare workers and skin sensitization: North-eastern Italian database. Occup Med (Lond). 2016;66(1):72-4, https://doi.org/10.1093/occmed/kqv139.

11. Gibbon KL, Mcfadden JP, Rycroft RJG, Ross JS, Chinn S, White IR. Changing frequency of thiuram allergy in healthcare workers with hand dermatitis. Br J Dermatol. 2003;144(2):347-50, https://doi.org/10.1046/j.13652133.2001.04024.x.

12. Geier J, Lessmann H, Mahler V, Pohrt U, Uter W, Schnuch A. Occupational contact allergy caused by rubber gloves Nothing has changed. Contact Dermat. 2012;67(3):14956, https://doi.org/10.1111/j.1600-0536.2012.02139.x.

13. Geier J, Lessmann H, Uter W, Schnuch A. Occupational rubber glove allergy: Results of the Information Network of Departments of Dermatology (IVDK), 1995-2001. Contact Dermat. 2003;48(1):39-44, https://doi.org/10.1034/ j.1600-0536.2003.480107.x.

14. Gokalp H, Kaya K. Angioedema-like allergic contact dermatitis related to black henna. Dermatol Online J. 2014; 20(2):16.

15. Broides A, Sofer S, Lazar I. Contact dermatitis with severe scalp swelling and upper airway compromise due to black 
henna hair dye. Pediatr Emerg Care. 2011;27(8):745-6, https://doi.org/10.1097/PEC.0b013e318226df18.

16. Schwensen JF, Menné T, Johansen JD, Thyssen JP. Persistent periorbital allergic contact dermatitis in a dental technician caused by airborne thiuram exposure. Contact Dermat. 2015;73:321-32, https://doi.org/10.1111/cod.12443.

17. Jensen P, Menné T, Thyssen JP. Allergic contact dermatitis in a nurse caused by airborne rubber additives. Contact Dermat. 2011;65(1):54-5, https://doi.org/10.1111/j.16000536.2011.01914.x.

18. Higgins C, Nixon R. Facial allergic contact dermatitis without hand involvement caused by disposable latex gloves. Contact Dermat. 2016;74:246-56, https://doi.org/ 10.1111/cod.12502.

19. Cao LY, Taylor JS, Sood A, et al. Allergic contact dermatitis to synthetic rubber gloves. Changing trends in patch test reactions to accelerators. Arch Dermatol. 2010;146 (9):1001-7, https://doi.org/10.1001/archdermatol.2010.219.
20. Widman TJ, Oostman H, Storrs FJ. Allergic contact dermatitis from medical adhesive bandages in patients who report having a reaction to medical bandages. Dermatitis 2008;19(1):32-7.

21. Wrangsjö K, Osterman K, van Hage-Hamsten M. Glove-related skin symptoms among operating theatre and dental care unit personnel. Contact Dermat. 1994:30(2):102-7, https://doi.org/10.1111/j.1600-0536.1994.tb00572.x.

22. Fisher AA. Management of dermatitis due to surgical gloves. J Dermatol Surg Oncol. 1985;11(6):628-31, https:// doi.org/10.1111/j.1524-4725.1985.tb01907.x.

23. Magnavita N. Work-related symptoms in indoor environment: A puzzling problem for the occupational physician. Int Arch Occup Environ Health. 2015;88(2):185-96, https://doi.org/10.1007/s00420-014-0952-7.

This work is available in Open Access model and licensed under a Creative Commons Attribution-NonCommercial 3.0 Poland License - http://creativecommons.org/licenses/by-nc/3.0/pl/deed.en. 